\title{
Perluasan Indeks Seleksi Nilai Fenotipe Untuk Indeks Seleksi Nilai Pemuliaan
}

\section{Edizon Jambormias $^{1 *}$, Surjono Hadi Sutjahjo ${ }^{2}$, Ahmad Ansori Mattjik ${ }^{3}$, Yudiwanti Wahyu², Desta Wirnas $^{2}$}

\author{
${ }^{1}$ Program Studi Agroteknologi, Fakultas Pertanian, Universitas Pattimura, Ambon. \\ ${ }^{2}$ Departemen Agronomi dan Hortikultura, Fakultas Pertanian, Institut Pertanian Bogor \\ (Bogor Agricultural University), Jl. Meranti, Kampus IPB Dramaga, Bogor 16680, Indonesia \\ Telp \& Faks.62-251-8629353 e-mail agronipb@indo.net.id \\ ${ }^{3}$ Departemen Statistika, Fakultas Matematika dan Ilmu Pengetahuan Alam, Institut Pertanian Bogor. (Bogor \\ Agricultural University), Jl. Lingkar Kampus, Kampus IPB Dramaga, Bogor 16680, Indonesia \\ *)Penulis untuk korespondensi : edy_jambormias@yahoo.com
}

Disetujui 24 Desember 2013/ Published online 13 Februari 2014

\begin{abstract}
ABSTRAK
Indeks seleksi merupakan salah satu prosedur seleksi sifat berganda yang penting dalam program pemuliaan tanaman. Tulisan ini bertujuan untuk mendeskripsi dan menduga parameter-parameter skor indeks dari metode-metode indeks seleksi nilai fenotipe, dan kemungkinan perluasannya bagi metode indeks seleksi nilai pemuliaan BLUP. Peragam fenotipe dan genotipe dari indeks basis dan Smith-Hazel digunakan sebagai landasan statistik untuk pendugaan parameter dan perluasan penggunaan indeks. Penurunan rumus menghasilkan peragam aditif dan fenotipe bagi indeks seleksi berbasis nilai eigen, dan memperoleh parameter indeks seperti heritabilitas, koefisien determinasi, respons seleksi, respons seleksi tak langsung dan respons komponen sifat-sifat kuantitatif bagi semua metode indeks nilai fenotipe. Parameter peragam nilai pemuliaan sebenarnya dapat diduga dari analisis eigen dan keakuratan nilai pemuliaan BLUP yang memungkinkan metode indeks seleksi nilai fenotipe dapat diterapkan dengan prosedur yang sama pada nilai pemuliaan BLUP. Terakhir, heritabilitas dan koefisien determinasi indeks dapat digunakan dalam simulasi pembobot ekonomis untuk menghasilkan indeks terbaik.
\end{abstract}

Kata kunci: indeks seleksi, nilai pemuliaan sebenarnya, nilai pemuliaan empiris, peubah kategorik.

\section{ABSTRACT}

Selection index is one of the multiple traits selection procedures that are important in plant breeding programs. This paper aims to describe and estimate the index score parameters of the selection index methods of phenotype value, and the possibility to expand its methods for BLUP breeding value. Covariance phenotypic and genotypic approach in base index and the Smith-Hazel index were used as the statistical basis for estimating parameters and expansion the uses of the index. The derivative formula produces both additive and phenotypic covariance for the index based on eigenanalysis, and gaining the parameter of indexes such as the heritability, coefficient of determination, response to selection, indirect response to selection, and response components of quantitative traits of all indexes methods and its expansion. The additive covariance parameters of true breeding values can be expanded of the eigenanalysis of additive covariance and accuracy of BLUP breeding values that allows the selection index methods of the phenotypic values can be applied with similar procedure to BLUP breeding values. Finally, heritabilities or coefficient of determination of indexes can be uses in a simulation of economic weight to producing the best index.

Keywords: selection index, true breeding value, empirical breeding value, categorical variables.

\section{PENDAHULUAN}

Keberhasilan seleksi bergantung pada seberapa besar faktor genetik diterjemahkan ke dalam suatu nilai bersama (merit value) yang merepresentasikan keunggulan menyeluruh suatu bahan genetik. Seleksi dilakukan terhadap nilai fenotipe (phenotypic value), tetapi nilai pemuliaan 
(breeding value) yang terpilih. Indeks seleksi Smith-Hazel merupakan pendekatan yang dapat digunakan untuk memperoleh nilai bersama ini. Matriks peragam genotipe berperanan penting dalam penyusunan indeks ini yang mampu mengoptimalkan nilai pemuliaan (Smith, 1936; Hazel, 1943; Kemphtorne \& Nordskog, 1959; Cerón-Rojas et al., 2006, Cerón-Rojas et al., 2008).

Indeks seleksi semakin akurat apabila menggunakan nilai pemuliaan. Nilai ini merupakan prediksi tak bias linear terbaik (best linear unbiased prediction, BLUP) dari kelas model linear campuran (mixed linear model) (McCulloch dan Searle, 2001; Myers et al. 2010, Gbur et al., 2012). Nilai pemuliaan BLUP bila diasumsikan merupakan nilai pemuliaan sebenarnya (true breeding value, TBV), maka seleksi dapat dilakukan menurut indeks basis (base index) yang menghasilkan diferensial indeks seleksi sama dengan respons seleksinya. Nilai ini sama dengan rata-rata skor indeks seleksi yang terpilih dalam seleksi (Walsh, 2013, Komunikasi Pribadi). Akibatnya keakuratan indeks seleksi adalah $100 \%$ untuk berbagai kemungkinan simulasi pembobot ekonomis, karena indeks seleksi basis mengabaikan heritabilitas dan korelasi antar sifat.

Nilai pemuliaan BLUP selain merupakan TBV, juga diasumsikan merupakan nilai pemuliaan empiris (empirical breeding value, EBV) (Muir 2007). Indeks seleksi Smith-Hazel diperlukan untuk memaksimumkan EBV dan TBV, sehingga sifat-sifat bernilai ekonomis penting seperti hasil (yield) dapat terseleksi secara baik. Sifat-sifat bernilai ekonomis cenderung memiliki heritabilitas rendah dan dipengaruhi banyak sifat lain (Sarwar et al., 2004), sehingga memerlukan seleksi sifat berkorelasi. Seleksi terhadap suatu sifat secara partikuler, menyebabkan sifat-sifat yang lain turut mengalami perubahan karena korelasi antar sifat itu (Lande dan Arnold, 1983). Oleh sebab itu diperlukan perluasan indeks seleksi Smith-Hazel bagi nilai pemuliaan BLUP yang dapat memanfaatkan korelasi antar sifat.

Tulisan ini bertujuan untuk mendeskripsi dan menduga parameter-parameter indeks dari metode-metode indeks seleksi nilai fenotipe, dan kemungkinan perluasannya bagi metode indeks seleksi nilai pemuliaan BLUP.

\section{NILAI PEMULIAAN BLUP}

BLUP pada awalnya dikembangkan untuk tujuan seleksi dalam pemuliaan ternak (Mrode dan
Thompson, 2005) dan sekarang banyak digunakan di berbagai bidang penelitian. BLUP juga dapat digunakan untuk seleksi dalam pemuliaan tanaman dan pengujian varietas (Piepho et al., 2008). Potensi keuntungan seleksi BLUP dalam pemuliaan tanaman sangat besar (Heffner et al. 2009), namun pemulia tanaman tergolong lamban dalam mengadopsi metode ini (Piepho et al., 2008). BLUP merupakan pendugaan dari suatu pengaruh acak dalam model linear campuran (Searle et al., 1992; Mc Culloh dan Searle, 2001). Perbedaan dengan model linear umum (general linear model) yang sering digunakan adalah adanya pembobotan pengaruh acak dengan suatu pembobot nisbah dari hasil penguraian harapan kuadrat tengah, yang dalam hal ini adalah heritabilitas (Galwey, 2006, Piepho et al., 2008). Jika heritabilitas tinggi, BLUP cenderung mendekati nilai fenotipe, tetapi bila rendah akan cenderung menyusut (shrink). Penyusutan ini diantisipasi melalui pendugaan parameter berbasis metode kemungkinan maksimum (maximum likelihood) (Searle et al., 1992). BLUP efektif mengantisipasi heteroskedatisitas (Gbur et al., 2012) dan dapat memaksimalkan korelasi antara nilai amatan dengan nilai prediksi (Searle et al., 1992). Bila faktor acak merupakan bahan genetik, maka BLUP merupakan suatu nilai pemuliaan (Satoh, 1998; Bauer et al., 2006).

BLUP juga dapat dihasilkan dari data tak setimbang dan asumsi kenormalan tak terpenuhi. McCullagh dan Nelder (1987) mengembangkan kelas model linear terampat (generalized linear models) untuk menangani data seperti ini. Perluasan dengan model linear campuran menghasilkan kelas model linear campuran terampat (generalized linear mixed models) yang cocok dengan famili sebaran eksponensial (Myers et al., 2010; Gbur et al., 2012). Famili sebaran ini meliputi sebaran normal, log normal, eksponensial, gamma, non-sentral $t$, invers-normal, beta, binom, binom negatif, geometrik, poisson, dan multinom (Gbur et al., 2012). Perluasan kelas model linear terampat dengan model transformasi Box-Cox menghasilkan kelas model linear terampat tertransformasi (transformed-generalized linear models) (Cordeiro dan de Andrade, 2009) yang dapat menangani permasalahan ketaknormalan di luar famili sebaran eksponensial. Kelas pemodelan ini juga dapat diperluas sebagai kelas model campuran linear terampat tertransformasi (transformed generalized linear mixed models) atau disederhanakan menjadi kelas model campuran linear tertransformasi (transformed linear mixed models). 


\section{LANDASAN TEORI INDEKS SELEKSI}

\section{Indeks Seleksi Basis dan Smith-Hazel}

Secara umum, seleksi nilai fenotipe terbaik yang digunakan dalam program pemuliaan tanaman menggunakan indeks basis (base index) (Panse, 1946; Brim et al., 1959; Williams, 1962a,b) dan indeks Smith-Hazel (Smith, 1936; Hazel, 1943). Indeks basis $\left(I_{b}\right)$ dinyatakan dalam bentuk persamaan (Walsh, 2010):

dengan ragam indeks:

$$
I=\sum a_{i} z_{i}=\mathbf{a}^{\prime} \mathbf{z}
$$

$$
\sigma_{I}^{2}=\sigma_{\left(\mathbf{a}^{\prime} \mathbf{z}, \mathbf{a}^{\prime} \mathbf{z}\right)}=\mathbf{a}^{\prime} \sigma_{(\mathbf{z}, \mathbf{z})} \mathbf{a}=\mathbf{a}^{\prime} \mathbf{P a}
$$

dimana $I=$ indeks basis, $a_{i}=$ pembobot nilai fenotipe peubah ke- $i$, dan $z_{i}=$ nilai fenotipe peubah ke- $i$. Dalam bentuk matriks, $\mathbf{a}=\left(\begin{array}{lll}a_{1} & a_{2} & \ldots\end{array}\right.$ $\left.a_{p}\right)^{\prime}=$ vektor pembobot nilai fenotipe, $\mathbf{P}=$ matriks peragam fenotipe berdimensi $(p \times p)$, dan $\mathbf{z}=\left(z_{1}\right.$ $\left.\begin{array}{llll}z_{2} & \ldots & z_{p}\end{array}\right)^{\prime}=$ nilai fenotipe.

Bila menggunakan populasi yang diketahui informasi kekerabatannya (information from relatives) atau populasi rancangan persilangan dan rancangan percobaan, maka ragam aditif indeks adalah:

$$
\sigma_{I(A)}^{2}=\sigma_{A\left(\mathbf{a}^{\prime} \mathbf{z}, \mathbf{a}^{\prime} \mathbf{z}\right)}=\mathbf{a}^{\prime} \sigma_{A(\mathbf{z}, \mathbf{z})} \mathbf{a}=\mathbf{a}^{\prime} \mathbf{G a}
$$

dimana $\mathbf{G}=$ matriks peragam aditif berdimensi $(p \times p)$.

Perolehan ragam aditif indeks memungkinkan diperolehnya heritabilitas indeks $\left(h_{I}^{2}\right)$, respons seleksi indeks $\left(R_{I}\right)$ dan respons seleksi komponen $\left(\underline{R}_{\mathrm{C}}\right)$, masing-masing menurut persamaan (Walsh, 2010):

$$
\begin{gathered}
h_{I}^{2}=\sigma_{I(A)}^{2} / \sigma_{I}^{2}=\left(\mathbf{a}^{\prime} \mathbf{G a}\right) /\left(\mathbf{a}^{\prime} \mathbf{P a}\right) \\
R_{I}=i h^{2} \sigma_{P}=i\left(\mathbf{a}^{\prime} \mathbf{G a} / \mathbf{a}^{\prime} \mathbf{P a}\right) \sqrt{\mathbf{a}^{\prime} \mathbf{P a}}=i \mathbf{a}^{\prime} \mathbf{G a} / \sqrt{\mathbf{a}^{\prime} \mathbf{P a}} \\
\underline{R}_{C}=\mathbf{G P}^{-1} \mathbf{S}=\mathbf{G P}^{-1}\left(i / \sigma_{I}\right) \mathbf{P a}=\left(i / \sigma_{I}\right) \mathbf{G a}=i \mathbf{G a} / \sqrt{\mathbf{a}^{\prime} \mathbf{P a}},
\end{gathered}
$$

dimana untuk $\mathrm{S}=i / \sigma_{I} \mathbf{P a}=$ diferensial seleksi.

Indeks seleksi Smith-Hazel merupakan indeks bersama nilai fenotipe dan nilai pemuliaan. Berbeda dengan indeks basis yang hanya memperhatikan nilai fenotipe, indeks Smith-Hazel menggunakan indeks nilai fenotipe yang diketahui dan indeks nilai pemuliaan yang tidak diketahui, melalui pemaksimuman korelasi antara kedua indeks ini. Indeks nilai fenotipe dan indeks nilai pemuliaan masing-masing mengambil bentuk $I=$ $\sum b_{i} z_{i}=\mathbf{b}$ 'z dan $H=\sum a_{i} g_{i}=\mathbf{a}$ 'g. Korelasi indeks bersama, yaitu $\sigma_{H I}^{2}$, mencapai maksimum ketika:

$$
\mathbf{b}^{\prime} \mathbf{z}=\mathbf{a}^{\prime} \mathbf{g}
$$

$\operatorname{dimana} \mathbf{z}^{\prime}=\left(\begin{array}{llll}z_{1} & z_{2} & \ldots & z_{p}\end{array}\right)^{\prime}$ dan $\mathbf{b}^{\prime}=\left(\begin{array}{lllll}b_{1} & b_{2} & \ldots & b_{p}\end{array}\right)^{\prime}$ masing-masing adalah vektor nilai fenotipe dan vektor pembobot nilai fenotipe, sedangkan $\mathbf{g}^{\prime}=$ $\left(\begin{array}{llll}g_{1} & g_{2} & \ldots & g_{q}\end{array}\right)^{\prime}$ dan $\mathbf{a}^{\prime}=\left(\begin{array}{llll}a_{1} & a_{2} & \ldots & a_{q}\end{array}\right)^{\prime}$ masing-masing adalah vektor nilai genotipe dan vektor pembobot ekonomis, untuk serta $I=H$ (elemen sifat-sifat kuantitatif yang sama atau tumpang tindih sempurna), $I \approx H$ (elemen sifat-sifat kuantitatif sebagian sama atau tumpang tindih sebagian), dan $I \neq H$ (semua sifat kuantitatif berbeda atau tidak tumpang tindih) (Walsh, 2010).

Indeks Smith-Hazel mempunyai ragam indeks nilai fenotipe $\left(\sigma_{I}^{2}\right)$, ragam indeks nilai pemuliaan $\left(\sigma_{H}^{2}\right)$, dan peragam kedua indeks $\left(\sigma_{H I}\right)$, masing-masing adalah:

$$
\begin{aligned}
& \sigma_{I}^{2}=\sigma_{\left(\mathbf{b}^{\prime} \mathbf{z}, \mathbf{b}^{\prime} \mathbf{z}\right)}=\mathbf{b}^{\prime} \sigma_{(\mathbf{z}, \mathbf{z})} \mathbf{b}=\mathbf{b}^{\prime} \mathbf{P b} \\
& \sigma_{H}^{2}=\sigma_{\left(\mathbf{a}^{\prime} \mathbf{g}, \mathbf{a}^{\prime} \mathbf{g}\right)}=\mathbf{a}^{\prime} \sigma_{(\mathbf{g}, \mathbf{g})} \mathbf{a}=\mathbf{a}^{\prime} \mathbf{G a} \\
& \sigma_{H I}^{2}=\sigma_{\left(\mathbf{a}^{\prime} \mathbf{g}, \mathbf{b}^{\prime} \mathbf{z}\right)}=\mathbf{a}^{\prime} \sigma_{(\mathbf{g}, \mathbf{z})} \mathbf{b}=\mathbf{a}^{\prime} \mathbf{G b}
\end{aligned}
$$

dimana $\mathbf{P}=$ matriks peragam fenotipe berdimensi $(p \times p)$ dan $\mathbf{G}=$ matriks peragam aditif berdimensi $(p \times q)$, untuk $q \leq p \leq q$.

Korelasi antara indeks nilai pemuliaan dan indeks nilai fenotipe yang memaksimumkan indeks bersama dirumuskan sebagai:

$$
\rho_{H I}=\frac{\sigma_{H I}}{\sigma_{H} \sigma_{I}}=\frac{\mathbf{a}^{\prime} \mathbf{G b}}{\sqrt{\mathbf{a}^{\prime} \mathbf{G a}} \sqrt{\mathbf{b}^{\prime} \mathbf{P b}}} .
$$

Kuadrat dari persamaan ini, yaitu $\rho_{H I}^{2}$, merupakan koefisien determinasi.

Seleksi $I$ yang memaksimumkan $H$ dicapai melalui pemaksimuman pembobot indeks $\mathbf{b}$ yang memaksimumkan korelasi $\rho_{H I}$, diperoleh melalui pemaksimuman persamaan $\mathbf{a}^{\prime} \mathbf{G b} / \sqrt{\mathbf{b}^{\prime} \mathbf{P b}}$ yang menghasilkan skalar. Turunan pertama persamaan ini menghasilkan solusi nol terhadap $\overline{\mathbf{b}}$ yang sesuai dengan persamaan $\left(\overline{\mathbf{b}}^{\prime} \mathbf{P} \overline{\mathbf{b}}\right) \mathbf{G}$ 'a $=$ $\left(\mathbf{a}^{\prime} \mathbf{G} \overline{\mathbf{b}}\right) \mathbf{P} \overline{\mathbf{b}}$. Karena $\left(\overline{\mathbf{b}}^{\prime} \mathbf{P} \overline{\mathbf{b}}\right)$ dan $\mathbf{a}^{\prime} \mathbf{G} \overline{\mathbf{b}}$ adalah skalar, maka solusi bentuk persamaan $\mathbf{P} \overline{\mathbf{b}}=\mathbf{G}$ 'a memberikan vektor pembobot maksimum bagi indeks nilai fenotipe sebagai (Walsh, 2010):

$$
\mathbf{b}=\mathbf{P}^{-1} \mathbf{G} \mathbf{a}
$$

Pembobot ini menghasilkan indeks seleksi SmithHazel sebagai: 


$$
I_{s}=\mathbf{b}^{\prime} \mathbf{z}=\left(\mathbf{P}^{-1} \mathbf{G}^{\prime} \mathbf{a}\right)^{\prime} \mathbf{z}=\mathbf{a}^{\prime} \mathbf{G} \mathbf{P}^{-1} \mathbf{z}
$$

Secara umum, karena $\mathbf{b}=\mathbf{P}^{-1} \mathbf{G}^{\prime} \mathbf{a}$ maka $\mathbf{b}^{\prime} \mathbf{P b}=\left(\mathbf{P}^{-1} \mathbf{G}^{\prime} \mathbf{a}\right) \mathbf{P b}=\mathbf{a}^{\prime} \mathbf{G} \mathbf{P}^{-1} \mathbf{P b}=\mathbf{a}^{\prime} \mathbf{G b}$ sehingga beberapa parameter penting dalam seleksi juga bisa diketahui. Pertama, respons seleksi indeks bersama $\left(R_{H I}\right)$ yang merupakan suatu respons terkorelasi adalah (Walsh, 2010):

$$
\begin{aligned}
R_{H I}=i \sigma_{H} \rho_{H I} & =i \sigma_{H} \frac{\mathbf{a}^{\prime} \mathbf{G b}}{\sqrt{\mathbf{a}^{\prime} \mathbf{G a}} \sqrt{\mathbf{b}^{\prime} \mathbf{P b}}}=i \sqrt{\mathbf{a}^{\prime} \mathbf{G a}} \frac{\mathbf{a}^{\prime} \mathbf{G b}}{\sqrt{\mathbf{a}^{\prime} \mathbf{G a}} \sqrt{\mathbf{b}^{\prime} \mathbf{P b}}} \\
& =i \frac{\mathbf{a}^{\prime} \mathbf{G b}}{\sqrt{\mathbf{b}^{\prime} \mathbf{P b}}}=i \frac{\mathbf{b}^{\prime} \mathbf{P b}}{\sqrt{\mathbf{b}^{\prime} \mathbf{P b}}}=i \sqrt{\mathbf{b}^{\prime} \mathbf{P b}} .
\end{aligned}
$$

Kedua, respons seleksi komponen indeks $\left(\underline{R}_{C}\right)$ dan respons tak langsung indeks $H$ karena seleksi terhadap indeks $I$, yaitu $R_{H}$, masing-masing sebagai:

$$
\begin{aligned}
\underline{R}_{C} & =\left(i / \sigma_{I}\right) \mathbf{G b}=i(\mathbf{G b}) /\left(\sqrt{\mathbf{b}^{\prime} \mathbf{P b}}\right)=i(\mathbf{G b}) /\left(\sqrt{\mathbf{a}^{\prime} \mathbf{G b}}\right) \\
& =i\left(\mathbf{G P}^{-1} \mathbf{G}^{\prime} \mathbf{a}\right) /\left(\sqrt{\mathbf{a}^{\prime} \mathbf{G} \mathbf{P}^{-1} \mathbf{G}^{\prime} \mathbf{a}}\right) \\
R_{H} & =i\left(\mathbf{a}^{\prime} \mathbf{G b}\right) /\left(\sqrt{\mathbf{b}^{\prime} \mathbf{P b}}\right)=i\left(\mathbf{a}^{\prime} \mathbf{G b}\right) /\left(\sqrt{\mathbf{a}^{\prime} \mathbf{G b}}\right) \\
& =i \sqrt{\mathbf{a}^{\prime} \mathbf{G b}}=i \sqrt{\mathbf{a}^{\prime} \mathbf{G} \mathbf{P}^{-1} \mathbf{G}^{\prime} \mathbf{a}}=i \sigma_{I}
\end{aligned}
$$

Ketiga, peragam $\sigma_{H I}$ dan korelasi $\rho_{H I}$ masingmasing dapat disederhanakan menjadi:

$$
\begin{gathered}
\sigma_{H I}=\mathbf{a}^{\prime} \mathbf{G} \mathbf{b}=\mathbf{b}^{\prime} \mathbf{P b}=\sigma_{I}^{2} \\
\rho_{H I}=\sigma_{H I} / \sigma_{H} \sigma_{I}=\mathbf{a}^{\prime} \mathbf{G b} /\left(\sqrt{\mathbf{a}^{\prime} \mathbf{G a}} \sqrt{\mathbf{b}^{\prime} \mathbf{P b}}\right) \\
=\mathbf{b}^{\prime} \mathbf{P b} /\left(\sqrt{\mathbf{a}^{\prime} \mathbf{G a}} \sqrt{\mathbf{b}^{\prime} \mathbf{P b}}\right)=\sqrt{\mathbf{b}^{\prime} \mathbf{P b}} / \sqrt{\mathbf{a}^{\prime} \mathbf{G a}}=\sigma_{I} / \sigma_{H}
\end{gathered}
$$

Persamaan-persamaan ini, dan persamaan yang sama dari indeks basis, digunakan selanjutnya dalam perluasan kedua indeks, dengan $\mathbf{P}$ dan $\mathbf{G}$ digantikan oleh indeks peragam fenotipe dan aditif hasil perluasan.

\section{Metode-metode Indeks Seleksi Nilai Eigen}

Cerón-Rojas et al. (2006) mengembangkan metode indeks seleksi nilai eigen (eigenvalues selection index methods, ESIM) yang memaksimumkan nilai pemuliaan melalui persamaan ciri:

$$
\begin{gathered}
\mathbf{P b}=\lambda \mathbf{b} \\
(\mathbf{P}-\lambda \mathbf{I}) \mathbf{b}=0
\end{gathered}
$$

dimana $\lambda$ dan $\mathbf{b}$ adalah nilai eigen (akar ciri) dan vektor eigen (vektor ciri) dari matriks peragam (atau korelasi) fenotipe $\mathbf{P}$, dan $\mathbf{I}=$ matriks identitas. Indeks seleksi bagi ESIM adalah:

$$
I_{E}=\mathbf{b}^{\prime} \mathbf{z}
$$

dimana $\mathbf{z}=$ nilai fenotipe, dan vektor $\mathbf{b}=$ vektor ciri pertama dari persamaan ciri di atas. Respons seleksi $(\hat{R})$ ESIM yang equivalen dengan indeks Smith-Hazel adalah (Cerón-Rojas et al., 2006):

$$
\hat{R}=(i / \lambda) \sqrt{\mathbf{b}^{\prime} \mathbf{P b}}=i \sqrt{\mathbf{a}^{\prime} \mathbf{G} \mathbf{P}^{-1} \mathbf{P a}}=i / \sqrt{\lambda}
$$

Secara teknis, Mattjik et al. (2011) menggunakan analisis komponen utama (principal component analysis, PCA) untuk memilih $r$ komponen utama (principal component, PC) dari $p$ PC dengan keragaman optimum yang telah menjelaskan sebagian besar peragam data. Keragaman PC terpilih sebaiknya dapat menjelaskan sedikitnya $70-90 \%$ dari batas (cut off) keragaman total Jolliffe (2002). Analisis eigen dilakukan terhadap persamaan ciri:

$$
\mathbf{P k}=\lambda \mathbf{k}=(\mathbf{P}-\lambda \mathbf{I}) \mathbf{k}=0
$$

dengan kendala $\mathbf{k}_{i} \mathbf{k}_{i}^{\prime}=1$ dan $\mathbf{k}_{i} \mathbf{k}_{j}^{\prime}=0$, dimana $\mathbf{P}$ $=$ matriks peragam bila satuan peubah sama, atau matriks korelasi bila satuan peubah berbeda, $\mathbf{I}=$ matriks identitas, serta $\mathbf{k}=$ vektor eigen (vektor ciri) dan $\lambda=$ nilai eigen (akar ciri).

Analisis eigen menghasilkan akar ciri (eigen value $), \lambda^{\prime}=\left(\lambda_{1}>\lambda_{2}>\ldots \lambda_{j}>\ldots>\lambda_{p}\right)$ dan vektor ciri-vektor ciri (eigen vectors) $\left(\begin{array}{lllll}\mathbf{k}_{1} & \mathbf{k}_{2} & \ldots & \mathbf{k}_{j} & \ldots \\ \mathbf{k}_{p}\end{array}\right)$. Andaikan akar ciri $\lambda_{1}$ telah mencakup 70-90\% data, maka vektor ciri $\mathbf{k}_{1}=\left(\begin{array}{llll}k_{11} & k_{21} & \ldots & k_{p 1}\end{array}\right)$, merupakan vektor pembobot indeks a seperti pada ESIM. Namun bila keragaman tersebut baru tercapai setelah $\lambda_{q}^{\prime} \mathbf{1}_{q}$ akar ciri dari $\lambda_{p}^{\prime} \mathbf{1}_{p}$ total akar ciri, maka diperlukan metode untuk menggabungkan vektor $\begin{array}{llllll}\mathbf{k}_{1} & \mathbf{k}_{2} & \ldots & \mathbf{k}_{q} & \text { menjadi }\end{array}$ indeks a. Andaikan bobot masing-masing komponen PCA hingga $r$ komponen adalah (Mattik et al., 2011):

$$
\begin{gathered}
\mathrm{PC}_{1}=k_{1}^{\prime}=\mathrm{k}_{11} z_{1}+\mathrm{k}_{21} z_{2}+\ldots+\mathrm{k}_{i 1} z_{i}+\ldots+\mathrm{k}_{p 1} z_{p} \\
\mathrm{PC}_{2}=k_{2}^{\prime}=\mathrm{k}_{12} z_{1}+\mathrm{k}_{22} z_{2}+\ldots+\mathrm{k}_{i 2} z_{i}+\ldots+\mathrm{k}_{p 2} z_{p} \\
\ldots \\
\mathrm{PC}_{j}=k_{j}=\mathrm{k}_{1 j} z_{1}+\mathrm{k}_{2 j} z_{2}+\ldots+\mathrm{k}_{i j} z_{i}+\ldots+\mathrm{k}_{p j} z_{p} \\
\ldots \\
\mathrm{PC}_{q}=k_{q}^{\prime}=\mathrm{k}_{1 q} z_{1}+\mathrm{k}_{2 q} z_{2}+\ldots+\mathrm{k}_{i q} z_{i}+\ldots+\mathrm{k}_{p q} z_{p}
\end{gathered}
$$

maka pembobot untuk sifat kuantitatif $z_{i}$ adalah: $a_{i}=\sqrt{k_{i 1}^{2} / \lambda_{1}+k_{i 2}^{2} / \lambda_{2}+\ldots+k_{i j}^{2} / \lambda_{j}+\ldots+k_{i q}^{2} / \lambda_{q}}$.

Dalam bentuk penyelesaian persamaan matriks, vektor a diperoleh melalui persamaan:

$$
\mathbf{a}=\left[\boldsymbol{\Lambda}_{q}^{-1} \mathbf{1}_{q}\right]^{\prime} \mathbf{Q}^{\prime}
$$


dimana $=\boldsymbol{\Lambda}_{q}=\boldsymbol{\lambda}_{q} \mathbf{I}_{q}=$ matriks diagonal hingga $q$ PC, $\mathbf{1}_{q}=$ vektor satuan, dan $\mathbf{Q}=$ matriks berdimensi $(p \times q)$ untuk $q_{i j}=k_{i j}^{2}, \mathbf{I}_{q}=$ matriks identitas, dan $\lambda_{q}=$ akar ciri hingga $q$ PC.

Vektor a sesuai persamaan di atas selalu menghasilkan pembobot indeks yang positif dan melibatkan kombinasi lebih dari satu PC, sehingga berbeda dengan ESIM menurut CerónRojas et al. (2006) yang melibatkan hanya PC pertama (PC1), dimana terdapat elemen vektor ciri bernilai positif dan negatif. Karena berbeda dari ESIM, indeks ini dapat disebut sebagai metode indeks seleksi analisis komponen utama (principal component analysis of selection index methods, PCASIM) sesuai persamaan indeks: $I_{P C A}$ $=\mathbf{a}^{\prime} \mathbf{z}$.

\section{PERLUASAN INDEKS SELEKSI}

\section{Metode Indeks Seleksi Eigen Berbasis Indeks Smith Hazel}

Cerón-Rojas et al. (2006) menyebutkan bahwa ESIM tidak memerlukan pembobot ekonomis dan penduga ragam aditif dan fenotipe. Namun demikian, elemen-elemen akar ciri dari $q$ dan total $p$ PC merupakan ragam masing-masing PC. Andaikan akumulasi akar ciri dari $q$ dan total $p$ PC masing-masing merupakan ragam aditif dan fenotipe bersama dari $p$ sifat kuantitatif $z_{i}$, maka ekstraksi akar ciri masing-masing PC berdasarkan proporsi kontribusi vektor ciri PC itu dan akumulasinya menurut masing-masing sifat kuantitatif dapat menghasilkan matriks peragam aditif $(\boldsymbol{G})$ dan fenotipe $(\hat{\mathbf{P}})$.

Andaikan dari $\boldsymbol{\lambda}_{q}$ dan $\boldsymbol{\lambda}_{p}$ akar ciri analisis eigen dihasilkan masing-masing vektor ragam $\sigma_{q}^{2}=\left(\sigma_{(g) 1}^{2} \sigma_{(g) 2}^{2} \ldots \sigma_{(g) i}^{2} \ldots \sigma_{(g) p}^{2}\right)^{\prime}$ dan $\sigma_{p}^{2}=\left(\sigma_{(p) 1}^{2} \sigma_{(p) 2}^{2} \ldots \sigma_{(p) i}^{2} \ldots \sigma_{(p) p}^{2}\right)^{\prime}$ bagi sifat kuantitatif $z_{i}$, maka matriks peragam aditif dan fenotipe sifat-sifat kuantitatif masing-masing merupakan matriks peragam diagonal berdimensi $(p \times p)$ sesuai persamaan:

$$
\stackrel{\mathbf{G}}{=}=\sigma_{q}^{2} \mathbf{I}_{p} \text { dan } \hat{\mathbf{P}}=\sigma_{p}^{2} \mathbf{I}_{p}
$$

dimana $\sigma_{(g) i}^{2}=\sum_{j=1}^{q}\left(\sqrt{k_{i j}^{2}} / \sum_{j=1}^{q} \sum_{i=1}^{p} \sqrt{k_{i j}^{2}}\right) \lambda_{j} \quad$ dan $\sigma_{(p) i}^{2}=\sum_{j=1}^{p}\left(\sqrt{k_{i j}^{2}} / \sum_{j=1}^{p} \sum_{i=1}^{p} \sqrt{k_{i j}^{2}}\right) \lambda_{j}$, yaitu elemen sifat kuantitatif $z_{i}$ dalam vektor $\sigma_{q}^{2}$ dan $\sigma_{p}^{2}$. Misalnya ragam sifat kuantitatif $z_{1}$ adalah:

$$
\begin{aligned}
\sigma_{(g) 1}^{2} & =\left(\sqrt{k_{11}^{2}} /\left[\sqrt{k_{11}^{2}}+\sqrt{k_{21}^{2}}+\ldots+\sqrt{k_{p 1}^{2}}\right]\right) \lambda_{1} \\
& +\left(\sqrt{k_{12}^{2}} /\left[\sqrt{k_{12}^{2}}+\sqrt{k_{22}^{2}}+\ldots+\sqrt{k_{p 2}^{2}}\right]\right) \lambda_{2}+\ldots \\
& +\left(\sqrt{k_{1 q}^{2}} /\left[\sqrt{k_{1 q}^{2}}+\sqrt{k_{2 q}^{2}}+\ldots+\sqrt{k_{p q}^{2}}\right]\right) \lambda_{q} .
\end{aligned}
$$

Bila $\mathbf{P}=$ matriks korelasi nilai fenotipe, maka $\hat{\mathbf{P}}=\mathbf{I}_{p}$. Namun biasanya nilai eigen dan vektor eigen matriks korelasi pada beberapa PC bernilai sangat kecil, sehingga bila $\mathbf{P} \neq \mathbf{I}_{p}$, maka $\sigma_{(g) i}^{2}$ dan $\sigma_{(p) i}^{2}$ masing-masing dapat dinyatakan sebagai $\sum_{j=1}^{q}\left(k_{i j}^{2} / \sum_{j=1}^{q} \sum_{i=1}^{p} k_{i j}^{2}\right) \lambda_{j}$ dan $\sum_{j=1}^{p}\left(k_{i j}^{2} / \sum_{j=1}^{p} \sum_{i=1}^{p} k_{i j}^{2}\right) \lambda_{j}$ yang memenuhi $\mathbf{P}=\mathbf{I}_{p}$.

Perolehan peragam $\mathbf{G}$ dan $\mathbf{P}$ memungkinkan perluasan metode indeks seleksi Smith-Hazel dengan nilai eigen (Eigenvalue Smith-Hazel Selection Index Methods, ESSIM). Persamaan indeks nilai fenotipe dan pembobot indeks yang memaksimumkan indeks nilai pemuliaan masingmasing adalah: $I_{E S}=\mathbf{b}^{\prime} \mathbf{z}$ dan $\mathbf{b}=\hat{\mathbf{P}}^{-1} \mathbf{G} \mathbf{a}$.

\section{Perluasan Indeks Seleksi Smith-Hazel dengan Penambahan Peubah Kategorik}

Sifat-sifat penting lainnya adalah marker morfologi, isozim dan molekuler. Sifat-sifat ini merupakan peubah kategorik berskala nominal atau ordinal. Peubah-peubah ini dapat dilibatkan dalam indeks seleksi. Kuantifikasi peubah-peubah ini sebagai peubah skor (scoring variables) memungkinkan penyusunan indeks seleksi yang melibatkan sifat kuantitatif dan peubah kategorik secara serempak. Metode ini secara umum disebut metode seleksi sifat kuantitatif-peubah kategorik (categorical-quantitative traits selection index 
methods, CQSIM). Misalnya skor suatu marker molekuler diberikan oleh jumlah produk pengaruh aditif dugaan quantity traits loci (QTL) yang terpaut dengan marker molekuler (MQTL) dikali dengan kode nilai dari marker molekuler padanannya (Cerón-Rojas et al., 2008). Suatu teladan indeks seleksi dengan peubah kategorik adalah metode indeks seleksi molekuler (molecular selection index, MSI) menurut Lande dan Thompson (1990). MSI memasukkan beberapa marker molekuler yang berasosiasi dengan QTL ke dalam indeks. Bila tidak tersedia informasi seperti jumlah produk pada marker molekuler di atas, skor marker dapat menggunakan metode kuantifikasi yang lain, misalnya peubah biner ( $1=$ ada, $0=$ tidak ada), atau kontras (1=ada, $-1=$ tidak ada).

Indeks bersama dalam CQSIM adalah

$$
I_{C Q}=\mathbf{b}_{t}^{\prime} \mathbf{z}+\mathbf{b}_{c}^{\prime} \mathbf{c} \text { dan } H_{C Q}=\mathbf{a}_{t}^{\prime} \mathbf{g}+\mathbf{a}_{c}^{\prime} \mathbf{c}
$$

dimana $\mathbf{b}_{t}^{\prime}=\left(\begin{array}{llll}b_{1} & b_{2} & \ldots & b_{p}\end{array}\right)=$ vektor nilai fenotipe dan $\mathbf{b}_{c}^{\prime}=\left(\begin{array}{llll}b_{p+1} & b_{p+2} & \ldots & b_{c}\end{array}\right)$ vektor peubah kategorik, $\mathbf{a}_{t}^{\prime}=\left(\begin{array}{llll}a_{1} & a_{2} & \ldots & a_{q}\end{array}\right)=$ vektor pembobot ekonomis sifat kuantitatif yang diperbaiki, $\mathbf{a}_{c}=$ $\left(\begin{array}{llll}a_{q+1} & a_{q+2} & \ldots & a_{m}\end{array}\right)=$ vektor nol, $\mathbf{z}=\left(\begin{array}{llll}z_{1} & z_{2} & \ldots & z_{p}\end{array}\right)=$ nilai fenotipe yang diseleksi, $\mathbf{g}=\left(\begin{array}{llll}g_{1} & g_{2} & \ldots & g_{q}\end{array}\right)=$ vektor nilai pemuliaan yang dimaksimumkan, dan $\mathbf{c}=$ vektor peubah kategorik.

Pembobot indeks b yang memaksimumkan nilai pemuliaan $H_{C Q}$ adalah (Lande dan Thompson, 1990):

$$
\mathbf{b}=\mathbf{P}_{C}^{-1} \mathbf{G}_{C} \mathbf{a}
$$

$\operatorname{dimana} \mathbf{b}^{\prime}=\left(\begin{array}{ll}\mathbf{b}_{t}^{\prime} & \mathbf{b}_{c}^{\prime}\end{array}\right), \mathbf{G}_{C}=\left(\begin{array}{cc}\mathbf{G} & \mathbf{C}_{p}^{\prime} \\ \mathbf{C}_{p} & \mathbf{C}\end{array}\right)$, $\mathbf{P}_{C}=\left(\begin{array}{cc}\mathbf{P} & \mathbf{C}_{p}^{\prime} \\ \mathbf{C}_{p} & \mathbf{C}\end{array}\right)$ dan $\mathbf{a}^{\prime}=\left(\begin{array}{ll}\mathbf{a}_{t}^{\prime} & \mathbf{a}_{c}^{\prime}\end{array}\right)$, untuk $\mathbf{P}$ dan

G masing-masing adalah matriks peragam nilai fenotipe dan genotipe. $\mathbf{C}_{p}=$ matriks peragam peubah kategorik dan sifat kuantitatif berdimensi $c \times p$, untuk $c=$ banyaknya peubah kategorik, dan $\mathbf{C}=$ matriks peragam peubah kategorik berdimensi $c \times c$.

Perluasan Indeks Seleksi Nilai Eigen dengan Penambahan Peubah Kategorik

Analisis eigen juga dapat diperluas untuk menangani data percobaan dengan peubah kategorik. Pendekatan ini juga mirip dengan laporan Cerón-Rojas et al. (2008) yang menggunakan analisis eigen untuk memperluas pendekatan ESIM dengan indeks restriksi (Kemphtorne dan Nordskog, 1959), dan menghasilkan metode indeks seleksi nilai eigen molekuler (molecular eigenvalues selection index methods, MESIM) untuk sifat-sifat kuantitatif dan peubah kategorik penanda molekuler.

Perluasan PCASIM menghasilkan metode indeks seleksi nilai eigen sifat kuantitatifkategorik (categorical-quantitative traits eigenanalysis of selection index methods, CQESIM) dengan persamaan indeks:

$$
I_{C Q E}=\mathbf{a}_{t}^{\prime} \mathbf{z}+\mathbf{a}_{c}^{\prime} \mathbf{c}=\left(\begin{array}{ll}
\mathbf{a}_{t}^{\prime} & \mathbf{a}_{c}^{\prime}
\end{array}\right)\left(\begin{array}{ll}
\mathbf{z} & \mathbf{c}
\end{array}\right)
$$

dimana $\mathbf{a}_{t}^{\prime}=$ vektor pembobot nilai fenotipe, dihasilkan sama dengan prosedur PCASIM; $\mathbf{a}_{c}^{\prime}=$ vektor pembobot skor peubah kategorik yang mirip dengan $\mathbf{a}_{m}^{\prime}$ pada MSI (dapat juga bukan vektor nol), $\mathbf{z}=$ vektor nilai fenotipe; dan $\mathbf{c}^{\prime}=\left(c_{1}\right.$

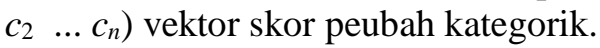

Peragam aditif dan fenotipe bagi CQ-ESIM adalah $\mathbf{G}_{\mathrm{C}}$ dan $\mathbf{P}_{C}$ seperti pada CQSIM. Pendugaan parameter CQ-ESIM selanjutnya berpadanan dengan indeks basis dan CQSIM.

Indeks sifat kuantitatif dan peubah kategorik juga dapat diperluas yang mirip dengan ESSIM sebagai metode indeks seleksi bersama analisis eigen sifat kuantitatif-peubah kategorik (categorical-quantitative traits eigenanalysis of merit selection index methods, CQ-EMSIM). Persamaan indeks seleksi ini adalah:

$$
I_{C Q E M}=\mathbf{b}_{t}^{\prime} \mathbf{z}+\mathbf{b}_{c}^{\prime} \mathbf{c}=\left(\begin{array}{ll}
\mathbf{b}_{t}^{\prime} & \mathbf{b}_{c}^{\prime}
\end{array}\right)\left(\begin{array}{ll}
\mathbf{z} & \mathbf{c}
\end{array}\right)
$$

dimana $\mathbf{b}_{t}^{\prime}=$ vektor pembobot indeks analisis eigen sifat kuantitatif, dihasilkan sama seperti analisis ESSIM; $\mathbf{b}_{c}^{\prime}=$ vektor pembobot skor peubah kategorik yang sama dengan $\mathbf{b}_{m}^{\prime}$ pada MSI, $\mathbf{z}=$ vektor nilai fenotipe; dan $\mathbf{c}^{\prime}=\left(\begin{array}{lll}c_{1} & c_{2} & \ldots\end{array}\right.$ $c_{n}$ ) vektor skor peubah kategorik.

Peragam fenotipe $\mathbf{P}_{C}$ dan aditif $\mathbf{G}_{C}$ yang bertalian dengan CQ-EMSIM ini sama dengan CQ-ESIM, tetapi dihasilkan dari prosedur yang sama seperti ESSIM.

Indeks Seleksi Kombinasi dan Indeks Seleksi Kombinasi dengan Peubah Kategorik

Seleksi kombinasi merupakan pendekatan seleksi yang melibatkan informasi antar famili dan dalam famili pada populasi berbasis informasi 
kekerabatan (Falconer dan Mackay, 1996). Metode indeks seleksi kombinasi (combined index selection methods, CISM) dan pembobot indeks yang memaksimumkan nilai pemuliaan antar famili dan dalam famili adalah:

$$
I_{C}=\mathbf{b}_{f}^{\prime} \mathbf{z}_{f}+\mathbf{b}_{w}^{\prime} \mathbf{z}_{w} \text { dan } \mathbf{b}=\mathbf{P}_{f w}^{-1} \mathbf{G}_{f w} \mathbf{a}
$$

$\operatorname{dimana} \mathbf{b}^{\prime}=\left(\begin{array}{ll}\mathbf{b}_{f}^{\prime} & \mathbf{b}_{w}^{\prime}\end{array}\right), \mathbf{G}_{f w}=\left(\begin{array}{cc}\mathbf{G}_{F} & \mathbf{0} \\ \mathbf{0} & \mathbf{G}_{W}\end{array}\right), \mathbf{P}_{f w}=$ $\left(\begin{array}{cc}\mathbf{P}_{F} & \mathbf{0} \\ \mathbf{0} & \mathbf{P}_{W}\end{array}\right)$ dan $\mathbf{a}^{\prime}=\left(\begin{array}{ll}\mathbf{a}_{f}^{\prime} & \mathbf{a}_{w}^{\prime}\end{array}\right)$,

untuk $\mathbf{b}_{f}=$ vektor pembobot nilai fenotipe antar famili, $\mathbf{b}_{w}=$ vektor pembobot nilai fenotipe dalam famili, $\mathbf{z}_{f}=$ simpangan rata-rata famili dari ratarata populasi, $\mathbf{z}_{w}=$ simpangan rata-rata individu dari rata-rata famili, $\mathbf{G}_{F}=r \mathbf{G}=$ peragam aditif antar famili, $\mathbf{G}_{W}=(1-r) \mathbf{G}=$ peragam aditif dalam famili, $\mathbf{P}_{F}=t \mathbf{P}=$ peragam fenotipe antar famili, $\mathbf{P}_{W}=(1-t) \mathbf{G}=$ peragam fenotipe dalam famili $[r=$ kemiripan antar kerabat (resemblance between relatives) dan $t=$ koefisien korelasi intra klas terampat $=$ teras $\mathbf{G} /$ teras $\mathbf{P}, \mathbf{G}$ dan $\mathbf{P}$ berpangkat penuh], $\mathbf{a}_{f}=$ vektor ekonomis nilai fenotipe antar famili, dan $\mathbf{a}_{w}=$ vektor ekonomis nilai fenotipe dalam famili. $\mathbf{P}$ dan $\mathbf{G}$ juga dapat mengambil bentuk $\mathbf{P}$ dan $\mathbf{G}$ dari analisis eigen.

Metode indeks seleksi kombinasi dengan peubah kategorik (combined-categorical quantitative traits of index selection methods, CCSIM) dikembangkan dari CISM menurut Falconer dan Mackay (1996) dan CQSIM menurut Lande dan Thompson (1990). Indeks CCSIM dan pembobot b yang memaksimumkan nilai pemuliaan adalah:

$$
\begin{gathered}
I_{C Q C}=\mathbf{b}_{f}^{\prime} \mathbf{z}_{f}+\mathbf{b}_{c f}^{\prime} \mathbf{c}_{f}+\mathbf{b}_{w}^{\prime} \mathbf{z}_{w}+\mathbf{b}_{c w}^{\prime} \mathbf{c}_{w} \text { dan } \\
\mathbf{b}=\mathbf{P}_{c f w}^{-1} \mathbf{G}_{c f w} \mathbf{a}
\end{gathered}
$$

dimana $\mathbf{b}^{\prime}=\left(\begin{array}{llll}\mathbf{b}_{f}^{\prime} & \mathbf{b}_{c}^{\prime} & \mathbf{b}_{w}^{\prime} & \mathbf{b}_{c}^{\prime}\end{array}\right)$ dan

$\mathbf{a}^{\prime}=\left(\begin{array}{llll}\mathbf{a}_{f}^{\prime} & \mathbf{a}_{c}^{\prime} & \mathbf{a}_{w}^{\prime} & \mathbf{a}_{c}^{\prime}\end{array}\right)$,

$\mathbf{G}_{c f w}=\left(\begin{array}{cccc}\mathbf{G}_{F} & \mathbf{C}_{p}^{\prime} & \mathbf{0} & \mathbf{0} \\ \mathbf{C}_{p} & \mathbf{C} & \mathbf{0} & \mathbf{0} \\ \mathbf{0} & \mathbf{0} & \mathbf{G}_{W} & \mathbf{C}_{p}^{\prime} \\ \mathbf{0} & \mathbf{0} & \mathbf{C}_{p} & \mathbf{C}\end{array}\right)$ dan
$\mathbf{P}_{c f w}=\left(\begin{array}{cccc}\mathbf{P}_{F} & \mathbf{C}_{p}^{\prime} & \mathbf{0} & \mathbf{0} \\ \mathbf{C}_{p} & \mathbf{C} & \mathbf{0} & \mathbf{0} \\ \mathbf{0} & \mathbf{0} & \mathbf{P}_{W} & \mathbf{C}_{p}^{\prime} \\ \mathbf{0} & \mathbf{0} & \mathbf{C}_{p} & \mathbf{C}\end{array}\right)$

sebagai peragam genotipe dan fenotipe dalam CCSIM.

\section{INDEKS SELEKSI NILAI PEMULIAAN}

\section{Indeks Seleksi Nilai Pemuliaan Sebenarnya}

Sebagaimana telah disinggung sebelumnya, BLUP merupakan nilai pemuliaan (Satoh, 1998; Bauer et al., 2006). Indeks seleksi nilai pemuliaan BLUP dapat diperluas dengan asumsi bahwa nilai ini merupakan nilai pemuliaan sebenarnya (true breeding value, TBV). Bila menggunakan asumsi ini, metode indeks seleksi basis dapat digunakan untuk menyusun indeks seleksi basis TBV (true breeding value selection index methods, TBVSIM) sesuai persamaan:

$$
I=\mathbf{a}^{\prime} \mathbf{g}
$$

dimana $\mathbf{g}=$ nilai pemuliaan BLUP, dan $\mathbf{a}=$ nilai ekonomis.

Persamaan $I=\mathbf{a}$ 'g memaksimumkan nilai pemuliaan $\mathbf{g}$ dengan vektor pembobot ekonomis a. Karena pemulia telah memprediksi g (yaitu BLUP), maka seleksi yang dilakukan adalah terhadap individu dengan skor I tertinggi, dengan respon harapan sama dengan rata-rata skor $I$ induk terpilih (Walsh, 2013, komunikasi pribadi). Akurasi TBVSIM adalah 100\% untuk berbagai nilai ekonomis a.

\section{Indeks Seleksi Nilai Pemuliaan Empiris dengan Nilai Eigen}

Indeks seleksi nilai pemuliaan BLUP juga dapat diperluas dengan asumsi bahwa nilai ini merupakan nilai pemuliaan empiris (empirical breeding value, EBV) (Muir, 2007). Metode indeks basis dan indeks Smith-Hazel serta beberapa perluasannya seperti PCASIM/ESIM, ESSIM, CQ-SIM, CQ-ESIM, dan CQ-EMSIM dapat digunakan pula untuk menyusun metode indeks seleksi nilai pemuliaan empiris (empirical breeding value selection index methods, EBVSIM).

EBVSIM bertujuan untuk memaksimumkan TBV yang tidak diketahui melalui seleksi EBV. Problema EBVSIM adalah tidak tersedianya peragam TBV yang memungkinkan penerapan persamaan indeks seleksi (kecuali indeks basis), 
dan perolehan parameter indeks seperti heritabilitas atau korelasi indeks bersama, respons seleksi, respons seleksi tak langsung dan respons seleksi komponen. Oleh sebab itu perolehan peragam aditif TBV, dinotasikan sebagai $\mathbf{A}$, merupakan kunci bagi seleksi EBVSIM dan perluasan-perluasannya.

Sedikitnya terdapat dua metode untuk menduga peragam $\mathbf{A}$, yaitu dengan menggunakan matriks peragam keakuratan nilai bersama BLUP dan analisis eigen. Metode pertama menggunakan persamaan:

$$
\mathbf{A}=R_{A \hat{A}}^{2} \mathbf{G},
$$

dimana $R_{A \hat{A}}^{2}=\mathbf{1}-\left(\mathbf{1}-\mathbf{G}^{-1} \mathrm{PEV}\right)=$ matriks peragam keakuratan nilai bersama BLUP, dalam hal PEV = $\mathbf{G}(\mathbf{1}-\mathbf{H})=$ matriks peragam galat prediksi (prediction error covariance matrices) berdimensi $(p \times p)$ (Phocas dan Colleau, 1996; Korsgaard et al., 2002), untuk $\mathbf{H}=$ matriks peragam koheritabilitas $=\mathbf{P}^{-1} \mathbf{G}$ berdimensi $(p \times p)$, dan $\mathbf{1}=$ suatu matriks satuan berdimensi $(p \times p)$. Dapat dibuktikan bahwa

$R_{A \hat{A}}^{2}=\mathbf{H}$.

Pendekatan kedua adalah melalui analisis eigen. Misalnya bila menggunakan EBVPCASIM/ESIM, maka persamaan indeks seleksi dan persamaan ciri untuk memperoleh pembobot a masing-masing adalah:

$$
\begin{gathered}
I=\mathbf{a}^{\prime} \mathbf{g} \\
\mathbf{G k}=\lambda \mathbf{k}=(\mathbf{G}-\lambda \mathbf{I}) \mathbf{k}=0
\end{gathered}
$$

dimana matriks peragam $\mathbf{P}$ pada persamaan ciri PCASIM/ESIM digantikan oleh matriks peragam G pada EBV-PCASIM/ESIM. Peragam aditif EBV dan TBV bagi EBV-PCASIM/ESIM dan perluasannya untuk kebutuhan pendugaan parameter indeks seleksi masing-masing adalah G dan Á.

Perolehan matriks A dan Á memungkinkan indeks bersama EBV dan TBV dapat dilakukan berpadanan dengan indeks basis (EBV-base index), indeks Smith-Hazel (EBV-Smith-Hazel index), indeks nilai eigen (EBV-PCASIM/ESIM), seleksi kombinasi (EBV-CSIM), dan perluasan dengan data kategorik dan sifat kuantitatif seperti EBV-CQSIM dan EBV-CCSIM.

\section{SIMULASI INDEKS SELEKSI TERBAIK}

Sebagian metode indeks seleksi dapat dilakukan simulasi nilai ekonomisnya untuk menghasilkan metode indeks seleksi terbaik dengan menggunakan koefisien determinasi indeks untuk mengukur keakuratan indeks (Moeljopawiro, 2002). Perbedaan metode indeks menghasilkan koefisien determinasi yang berbeda-beda. Metode indeks seleksi dengan asumsi nilai pemuliaan BLUP merupakan TBV mempunyai keakuratan indeks seleksi $100 \%$, sehingga tidak dapat dilakukan simulasi untuk memperoleh indeks terbaik. Metode indeks seleksi berbasis analisis eigen seperti PCASIM/ESIM dan CQ-ESIM merupakan metode indeks seleksi yang bergantung pada besarnya proporsi teras $\mathbf{G} /$ teras $\mathbf{P}$. Semakin banyak komponen $q$ yang dilibatkan, semakin baik keakuratan indeks. Akurasi mencapai $100 \%$ ketika $q=p$. Namun kemiringan plot perubahan $\lambda_{1}$ ke $\lambda_{2} \ldots$ yang landai hingga $\lambda_{q}$ menjadi patokan untuk memilih PCASIM/ESIM terbaik.

Metode indeks seleksi basis dan perluasannya, metode indeks Smith-Hazel dan perluasannya, dan metode indeks seleksi berbasis analisis eigen seperti ESSIM dan CQ-EMSIM merupakan metode-metode indeks seleksi yang keakuratannya bergantung pada besarnya heritabilitas indeks atau koefisien determinasi indeks. Simulasi nilai pembobot ekonomis yang berbeda-beda juga menghasilkan keakuratan yang berbeda-beda. Indeks terbaik adalah yang menghasilkan heritabilitas atau koefisien determinasi paling tinggi dengan laju perubahan yang besar.

\section{KESIMPULAN}

1. Kelas model linear campuran seperti model linear campuran, model linear campuran tertransformasi dan model campuran linear terampat dapat digunakan untuk membangkitkan nilai pemuliaan BLUP.

2. Indeks basis dan indeks Smith-Hazel mempunyai peragam aditif dan fenotipe yang dapat digunakan sebagai landasan teoritis untuk memperluas indeks seleksi fenotipe dan nilai pemuliaan BLUP.

3. Peragam aditif dan fenotipe dapat dibangkitkan dari indeks seleksi berbasis analisis eigen, yang memungkinkan pendugaan parameter indeks seperti heritabilitas, koefisien determinasi, respons seleksi, respons seleksi tak langsung dan respons seleksi komponen.

4. Indeks seleksi, pendugaan peragam aditif dan fenotipe, dan pendugaan parameter genetik dapat diperluas dengan melibatkan peubah kategorik seperti indeks seleksi kategorik, 
indeks seleksi kombinasi, dan indeks seleksi nilai eigen dengan peubah kategorik.

5. Indeks seleksi basis, indeks seleksi SmithHazel, indeks seleksi nilai eigen, indeks seleksi dengan peubah kategorik, indeks seleksi nilai eigen dengan peubah kategorik serta pendugaan parameter seleksi dapat diperluas mencakup nilai pemuliaan BLUP.

6. Beberapa indeks seleksi yang memiliki heritabilitas dan koefisien determinasi dapat dibuat simulasi pembobot ekonomisnya untuk memilih indeks terbaik.

\section{DAFTAR PUSTAKA}

Bauer, A.M., T.C. Reetz, \& J. Léon. 2006. Estimation of breeding value of inbred lines using best linear unbiased prediction (BLUP) and genetic similarities. Crop Sci. 46:2685-2691.

Brim, C.A., H.W. Johnson, C.C. Cokerkam. 1959. Multiple selection criteria in soybean. Agron. J. 51:42-46.

Cerón-Rojas, J.J., J. Crossa, J. SahagúnCastellanos, F. Castillo-Gonzáles, A. Santacruz-Verela. 2006. A selection index method based on eigenanalysis. Crop Sci. 46:1711-1721.

Cerón-Rojas, J.J., F. Castillo-González, J. Sahagún-Castellanos, A. Santacruz-Verela, I. Benitez-Riquelme, \& J. Crossa. 2008. A molecular selection index method based on eigenanalysis. Genetics 180: 547-557.

Cordeiro, G.M., \& M.G. de Andrade. 2009. Transformed generalized linear models. $J$. Stat. Plann. Inference 139: 2970-2987.

Falconer DS, Mackay TFC. 1996. Introduction to Quantitative Genetics (Ed 4). AdisonWesley Longman, Harlow UK.

Galwey, N.W. 2006. Introduction to Mixed Modeling. Beyond Regression and Analysis of Variance. John Wiley \& Sons Ltd., Chichester.

Gbur, E.E., W.W. Stroup, K.S. McCarter, S. Durham, L.J. Young, M. Christman, M. West, \& M. Kramer. 2012. Analysis of Generalized Linear Mixed Models in The Agricultural and Natural Resources Sciences. American Society of Agronomy, Soil Science Society of America, Crop Science Society of America, Inc., Madison.
Hazel, I.N. 1943. The genetic basis for constructing a selection indexes. Genetics 28:476-490.

Heffner, E.L., M.E. Sorrells, \& J.L. Jannink. 2009. Genomic selection for crop improvement. Crop Sci. 49:1-12.

Kemphtorne, O., \& A.W. Nordskog. 1959. Restricted selection indeces. Biometrics 15: 10-19.

Jolliffe, I.T. 2002. Principal Component Analysis. $2^{\text {nd }}$ ed. Springer, New York.

Korsgaard, I.R., A.H. Andersen, J. Jensen, 2002. Prediction error variance and expected response to selection, when selection is based on the best predictor - for Gaussian and threshold characters, traits folowing a Poisson mixed model and survival traits. Genet. Sel. Evol. 34:307-333.

Lande, R., \& R. Thompson. 1990. Efficiency of marker-assisted selection in the improvement of quantitative traits. Genetics 124:743-756.

Lande, R., S.J. Arnold, 1983. The measurement of selection on correlated characters. Evolution 1210-1226.

Mattjik, A.A., I.M. Sumertajaya, A.F. Hadi, G.N.A. Wibawa, 2011. Pemodelan Additive Main-effect \& Multiplicative Interaction (AMMI): Kini dan Yang Akan Datang. IPB Press, Bogor.

McCullagh, P., \& J.A. Nelder. 1989. Generalized Linear Models. Chapman and Hall, London.

McCulloch, C.E., \& S.R. Searle. 2001. Generalized, Linear and Mixed Models. John Wiley \& Sons. Inc., New York.

Moeljopawiro, S. 2002. Optimizing selection for yield using selection index. Zuriat. 13:3542.

Mrode, R.A., \& R. Thompson, 2005. Linear Models for the Prediction of Animal Breeding Values. $2^{\text {nd }}$ Ed. CABI Publishing, Walingword UK.

Muir, W.M. 2007. Comparison of genomic and traditional BLUP-estimated breeding value accuracy and selection response under alternative trait and genomic parameters. $J$. Anim. Breed. Genet. 124:342-355.

Myers, R.H., D.C. Montgomery, G.G. Vining, \& T.J. Robinson. 2010. Generalized Linear 
Models with Applications in Engineering and the Sciences. $2^{\text {nd }}$ Ed. A John Wiley and Sons, Inc. New Jersey.

Panse, V.G. 1946. An application of the discriminant function for selection in poultry. J. Genetics 47:242-248.

Phocas, F., \& J.J. Colleau. 1996. Genetic steadystate under BLUP selection for an infinite and homogenous population with discrete generations. Theor. Appl. Genet. 93:287294.

Piepho, H.P., J. Möhring, A.E. Melchinger, \& A. Bücshe, 2008. BLUP for phenotypic selection in plant breeding and variety testing. Euphytica 161: 209-228.

Sarwar,G., M.S. Sadiq, M. Saleem, G. Abbas . 2004. Selection criteria in $F_{3}$ and $F_{4}$ population of mungbean (Vigna radiata (L.) Wilczek). Pak. J. Bot. 36(2):297-310.

Satoh, 1998. A simple method of computing restricted best linear unbiased prediction of breeding values. Genet. Sel. Evol. 30: 89101.

Searle, S.R., G. Casella, \& C.E. McCulloch. 1992. Variance Components. Wiley, New York.

Smith, H.F. 1936. A discriminant function for plant selection. Ann. Eugen. 7: 240-250.

Walsh, B. 2010. Theory of Index Selection. Course of Quantitative Genetics of Selection Response. Wageningen University, the Netherlands. 7-11 June $2010 . \quad$ http://nitro.biosci.arizona.edu/workshops/Wag2010/pdf/Chapter33.p df

Williams, J.S. 1962a. Some statistical properties of a genetic selection index. Biometrika 49:325-337.

Williams, J.S. 1962b. The evaluation of the selection index. Biometrics 18:375-393. 